\title{
Development of a Titanium Plate for Mandibular Angle Fractures with a Bone Defect in the Lower Border: Finite Element Analysis and Mechanical Test
}

\author{
Douglas Rangel Goulart ${ }^{1}$, Daniel Takanori Kemmoku ${ }^{2}$, Pedro Yoshito Noritomi ${ }^{2}$, Márcio de Moraes ${ }^{1}$ \\ ${ }^{1}$ Department of Oral Diagnosis - Oral and Maxillofacial Surgery Division, Piracicaba Dental School, State University of \\ Campinas, Brazil. \\ ${ }^{2}$ Center for Information Techonology Renato Archer - CTI, Brazil.
}

\author{
Corresponding Author: \\ Márcio de Moraes \\ Piracicaba Dental School \\ Av. Limeira 901, Piracicaba - São Paulo \\ Brazil \\ Phone: +55 1921065390 \\ Fax: +55 1921065389 \\ E-mail: mmoraes@fop.unicamp.br
}

\begin{abstract}
Objectives: The aim of the present study was to develop a plate to treat mandibular angle fractures using the finite element method and mechanical testing.

Material and Methods: A three-dimensional model of a fractured mandible was generated using Rhinoceros 4.0 software. The models were exported to ANSYS ${ }^{\circledR}$, in which a static application of displacement $(3 \mathrm{~mm})$ was performed in the first molar region. Three groups were assessed according to the method of internal fixation ( $2 \mathrm{~mm}$ system): two non-locking plates; two locking plates and a new design locking plate. The computational model was transferred to an in vitro experiment with polyurethane mandibles. Each group contained five samples and was subjected to a linear loading test in a universal testing machine.

Results: A balanced distribution of stress was associated with the new plate design. This plate modified the mechanical behavior of the fractured region, with less displacement between the fractured segments. In the mechanical test, the group with two locking plates exhibited greater resistance to the $3 \mathrm{~mm}$ displacement, with a statistically significant difference when compared with the new plate group (ANOVA, $\mathrm{P}=0.016$ ).

Conclusions: The new plate exhibited a more balanced distribution of stress. However, the group with two locking plates exhibited greater mechanical resistance.
\end{abstract}

Keywords: facial injuries; finite element analysis; jaw fixation technics; fracture osteosynthesis.

Accepted for publication: 16 September 2015

To cite this article:

Goulart DR, Kemmoku DT, Noritomi PY, de Moraes M.

Development of a Titanium Plate for Mandibular Angle Fractures with a Bone Defect in the Lower Border: Finite Element Analysis and Mechanical Test.

J Oral Maxillofac Res 2015;6(3):e5.

URL: http://www.ejomr.org/JOMR/archives/2015/3/e5/v6n3e5.pdf

doi: $10.5037 /$ jomr.2015.6305 


\section{INTRODUCTION}

Fractures of the mandibular angle are the most problematic in the facial region due to the high frequency of complications after treatment. These complications mainly involve infections and nonunion [1]. Conceptually, stable fixation of the fragments minimizes sequestration while enabling post-operative function. In comminuted mandibular fractures, $2.4 \mathrm{~mm}$ locking plates are generally used, although the heavier variety of $2 \mathrm{~mm}$ locking plates is now becoming popular [2].

The plates employed should ensure functional, mechanical, and morphological rehabilitation [3] . The large number of studies on the treatment of mandibular angle fractures reflects the fact that a consensus has not been reached for a single, ideal treatment method. Biomechanical studies play an important role in improving the design and producing successful materials for medical and clinical purposes. The results of biomechanical studies do not always correspond to clinical outcomes and consequently, biomechanics are not the only factor to be considered when treating fractures [4]. Studies should try to simulate clinical conditions and parameters, which are more likely to provide the clinician with meaningful information [ [5].

The aim of the present study was to propose and analyse a three-dimensional finite element analysis (FEA) model to simulate the behaviour of a fractured mandible with a lost base segment, after reduction with osteosynthesis plates, in order to assess the displacement and stress fields. The results were used to support the design and development of a new osteosynthesis plate and to compare the mechanical behaviour of this plate with others in terms of the stabilization of fractured segments.

\section{MATERIAL AND METHODS}

The computer model of the mandible was constructed using Rhinoceros 4.0 software (McNeel North America, Seattle, WA) and was based on a previous three-dimensional model of a mandible taken from a data bank. The data bank model was created using images from the Multislice Helical Computed Tomography of human jaws (volunteers), with a cutting thickness of $1 \mathrm{~mm}$ [6]. The mandible was cut in the right side angle area to simulate a fracture with bone loss. In this model, the teeth were removed to simplify the modelling, and a geometric reference was created in the location of the right first molar on the alveolar ridge. This reference was used to mark the region for future displacement application. The computer model of the titanium plates and screws was developed based on a sketch of products from Tóride ${ }^{\circledR}$ (Tóride Indústria e Comércio Ltd, Mogi-Mirim, São Paulo - Brazil). The three-dimensional geometry of the plates and screws was created using Rhinoceros 4.0 software. One $2 \mathrm{~mm}$ locking plate was developed based on information acquired from the literature regarding stress distribution and the use of a single tension band plate in mandibular angle fractures $[7,8]$. The plate was modelled using SolidWorks ${ }^{\circledR} 2012$ X64 edition SP02 (Dassault Systèmes S.A, USA). This model was imported to Rhinoceros 4.0 and adjusted for the mandible model.

The mandibular fracture was fixed by three techniques of internal fixation: in Group I, one 4-hole $2 \mathrm{~mm}$ superior border plate was fixed with four screws with a $2 \mathrm{~mm}$ outer thread diameter (OTD) and a length of $6 \mathrm{~mm}$, while one 6-hole $2 \mathrm{~mm}$ inferior border plate was fixed with six $2 \mathrm{~mm}$ OTD, $12 \mathrm{~mm}$ long screws; in Group II, one 4-hole $2 \mathrm{~mm}$ locking superior border plate was fixed with four $2 \mathrm{~mm}$ OTD, $6 \mathrm{~mm}$ long locking screws, while one 6-hole $2 \mathrm{~mm}$ locking inferior border plate was fixed with six $2 \mathrm{~mm}$ OTD, $12 \mathrm{~mm}$ long locking screws; in Group III, one newly designed 8-hole $2 \mathrm{~mm}$ locking plate was fixed with eight $2 \mathrm{~mm}$ OTD, $6 \mathrm{~mm}$ long locking screws.

Each plate and screw needed to be in perfect contact with the bone. An attempt was made to place the plates according to standard clinical practice. Screws connecting the plates to the mandible were modelled without threads, with a diameter of $2 \mathrm{~mm}$ and a length that was appropriate for monocortical penetration $(6 \mathrm{~mm})$ on the superior border and bicortical penetration $(12 \mathrm{~mm})$ on the inferior border.

The geometry was imported to the Ansys ${ }^{\circledR}$ 14.0.1. 2.0 Framework (ANSYS ${ }^{\circledR}$ Inc., Houston, USA) to preprocess the finite element model. All of the materials were considered to be homogenous, isotropic and linear elastic [9]. We elected to model the bone geometry as one homogeneous phase, similar to the synthetic material used to produce the mandible applied in the mechanical tests (polyurethane). The properties used for the polyurethane mandibular substratum were based on an isotropic Young's modulus of $624.42 \mathrm{MPa}$ and a Poisson's ratio of 0.2817 [10]. The properties of the titanium plates and screws followed the data provided by the manufacturer: the screws were made of Titanium alloy (Titanium-6Aluminum-4Vanadium; ASTM F-136) and the plates were made of commercially pure Titanium (ASTM F67) (Table 1). 
Table 1. Properties of materials used in simulation at Ansys ${ }^{\circledR}$

\begin{tabular}{l|c|c}
\hline & $\begin{array}{c}\text { Young's modulus } \\
\text { (MPa) }\end{array}$ & Poisson's ratio \\
\hline $\begin{array}{l}\text { Mandible - cortical } \\
\text { and cancellous bone }\end{array}$ & 624.42 & 0.28 \\
\hline Titanium F136 & $1.138 \times 10^{5}$ & 0.34 \\
\hline Titanium F67 & $1.16 \times 10^{5}$ & 0.34 \\
\hline
\end{tabular}

The elements of the meshes used in the present study were quadratic tetrahedrons, generated with the following configurations: 1) mandibular ramus adjacent to the mandibular fracture, with a mean of $1 \mathrm{~mm}$ for the edge of each geometric element in the cortical bone and $2 \mathrm{~mm}$ for the edge of the trabecular bone; 2) body of mandible and the left mandible side with a mean edge of $2 \mathrm{~mm}$ for each geometric element; 3) plates and screws with a mean edge of 0.3 $\mathrm{mm}$ for each geometric element. The mean number of nodes and elements was 775,000 and 488,000, respectively.

The mandible was constrained for all axes in the region of the temporomandibular joint and the coronoid process on both sides. A displacement of $3 \mathrm{~mm}$ was applied to a point on the alveolar ridge, near the middle of the occlusal face of the first molar. The contact conditions between fractured segments were frictionless. The interaction between the plates and the heads of the conventional screws was considered frictionless. For the locking group, a perfectly glued (bonded) contact was applied. The interaction between the screws and the mandible was perfectly bonded.

Mechanical static structural analysis was carried out. In addition, the displacement at a specific point above the fracture line and the reaction load at the point of displacement were assessed. All stress values were given in Megapascals (MPa) and the reaction load was given in Newtons (N). A colour scale with stress values was used to qualitatively assess the stress distribution in plates and screws.

In the mechanical test a total of 15 synthetic polyurethane mandibles (Nacional Ossos, São Paulo, Brazil) were used in this investigation. One polyurethane mandible was sectioned at the right side angle, to simulate a fracture with a triangular defect in the base, using a diamond disc mounted on a hand piece. Subsequently, this model was sent to the factory for replication. The segment contained an isosceles triangle with the following dimensions: length of the side $-15 \mathrm{~mm}$; length of the inferior border defect - 10 $\mathrm{mm}$. Mandibles were randomly separated into three groups according to the fixation technique used, as described in the FEA model. The plates and screws

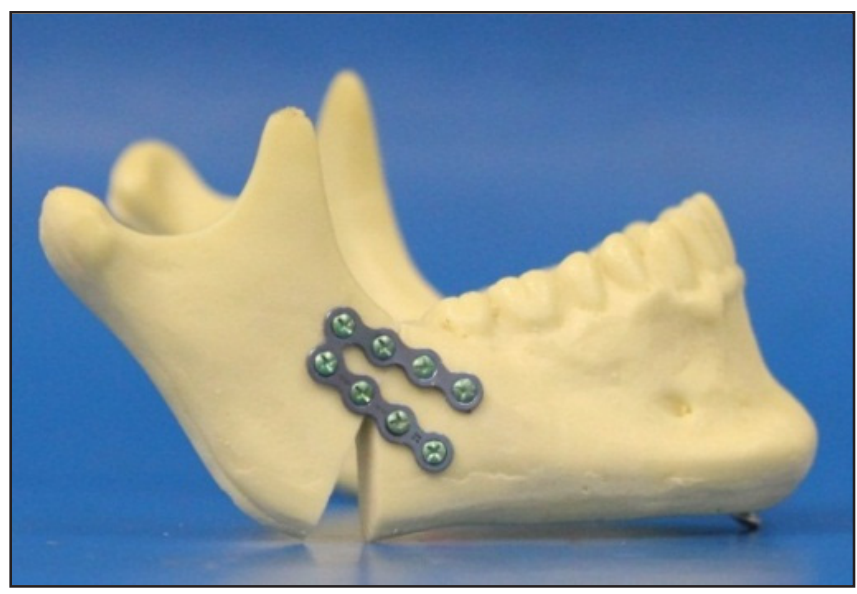

Figure 1. Right side lateral view of the polyurethane mandible, fixed according to Group III.

were fabricated by Tóride ${ }^{\circledR}$. Each group contained 5 polyurethane mandibles. Figure 1 displays one of the polyurethane mandibles (Group III).

The adaptation of the titanium-based plates to the mandible was ensured by using the specific instruments offered in the manufacturer's set. To standardize the position of the plate, acrylic jigs were made for each sub-group and adapted to the lateral aspect of the polyurethane mandibles during the fixation of the plate. The sample groups were submitted to a linear loading test in the upper and lower areas of the first molar region using the Instron 4411 (Instron Corp., Norwood, MA) servohydraulic material testing unit.

The mandibles were included in acrylic in a mechanical testing structure that was custom-made for the present study. In the testing structure, the condyle and coronoid processes were fixed on both sides while the loading was applied to the occlusal surface of the first molar on the same side of the fracture.

Instron 4411 produced linear displacement at a rate of $1 \mathrm{~mm} / \mathrm{min}$ and the loading was continuously applied up to $5 \mathrm{~mm}$ of displacement. Load data for the reaction force (Newtons) was obtained for 1, 3 and 5 $\mathrm{mm}$ of displacement.

\section{Statistical analysis}

In the FEA the results were descriptive regarding displacement of fractured segment, reaction load and equivalent Von Mises Stress distribution. In the mechanical test, parametric data were expressed as mean and standard deviation (M [SD]). These values were derived and compared for statistical significance within the attachment categories and then tested using analysis of variance (one-way ANOVA). Values were considered significant at $\mathrm{P}<0.05$. Mean values were compared using Tukey's test. 


\section{RESULTS}

It was clear that the lower plate was placed under less stress than the upper plate in the FEA. The stress was mostly concentrated in the area of the first distal screw and around the plates that crossed the fracture line in Groups I and II. The stress distribution was similar for locking and non-locking plates in terms of sharing the load among the screws: the screws at the extremities do not share load. In the Group III, there is a more homogeneous stress distribution along the plates; however, it was more pronounced between the second and third screws of the upper area of the plate. Figures 2 to 4 display the stress distribution for the three techniques studied. In this model,

\begin{tabular}{|c|}
\hline $\begin{array}{l}\text { Equivalent Stress } \\
\text { Type: Equivalent (von-Mises) Stress } \\
\text { Unit: MPa } \\
\text { Time: } 1 \\
\text { Max: } 18063 \\
\text { Min: } 0,00015277 \\
\qquad \begin{array}{|l}18500 \\
18500 \\
8157,8 \\
3597,3 \\
1586,3 \\
699,49 \\
308,45 \\
136,01 \\
59,977 \\
26,448 \\
11,663 \\
5,1427 \\
2,2678 \\
1 \\
0,00015277\end{array}\end{array}$ \\
\hline
\end{tabular}

Figure 2. Von Mises Stress scale.

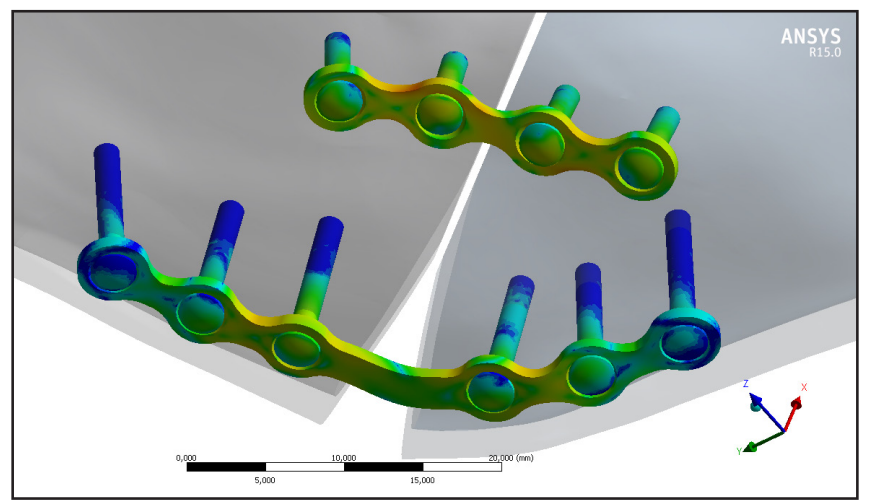

Figure 3. Equivalent Von Mises Stress distribution in plates and screws from Group I. the fractured mandibular body tended to rotate, maintaining the central contact between the fractured segments. The displacement in the geometric reference was similar in all three groups, while Group III exhibited lower displacement values on the $\mathrm{Y}$ and $\mathrm{Z}$ axes. Table 2 displays the results of the displacement with geometric references.

Group II exhibited the highest value of reaction force at specific displacement points. Table 3 displays the reaction force at the loading point of the three groups.

Table 2. Displacement of geometric reference $(\mathrm{mm})$ in the finite element analysis model

\begin{tabular}{l|c|c|c}
\hline \multirow{2}{*}{} & \multicolumn{3}{|c}{ Axis } \\
\cline { 2 - 4 } & $\mathbf{X}$ & $\mathbf{Y}$ & $\mathbf{Z}$ \\
\hline Group I & 0.69 & 0.51 & 1.98 \\
\hline Group II & 0.81 & 0.59 & 1.56 \\
\hline Group III & 0.74 & 0.28 & 1.47 \\
\hline
\end{tabular}

Table 3. Force reaction in simulation of $3 \mathrm{~mm}$ of displacement

\begin{tabular}{l|c}
\hline & Reaction force (N) \\
\hline Group I & 467.35 \\
\hline Group II & 651.67 \\
\hline Group III & 594.41 \\
\hline
\end{tabular}

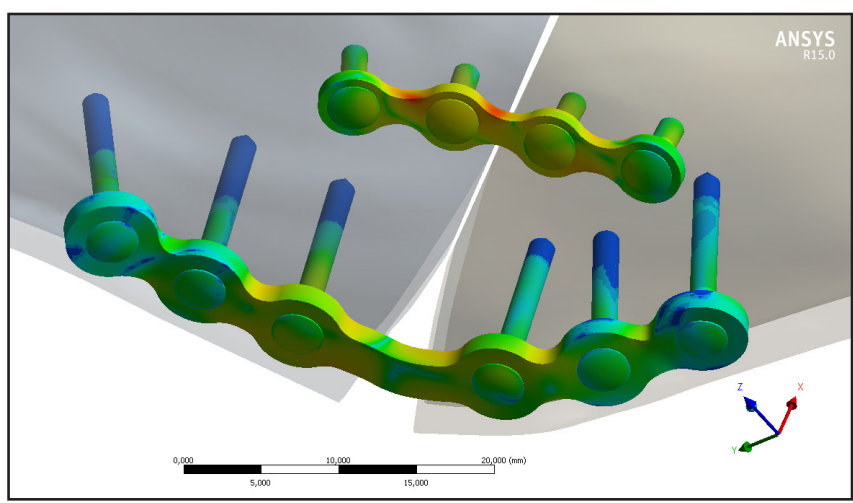

Figure 4. Equivalent Von Mises Stress distribution in plates and screws from Group II.

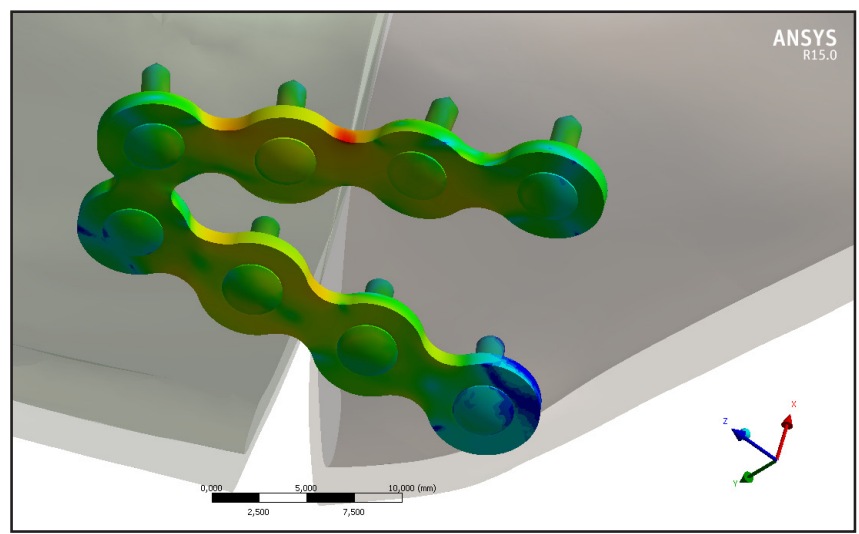

Figure 5. Equivalent Von Mises Stress distribution in plates and screws from Group III. 
In the mechanical test, fixation failure was not found in the groups with a displacement of $5 \mathrm{~mm}$. Table 4 displays the loading for groups related to displacement. For 1 and $5 \mathrm{~mm}$ of displacement, no statistically significant differences were found between the groups in the one-way ANOVA $(\mathrm{F}=2.03, \mathrm{P}=0.173 ; \mathrm{F}=3.11, \mathrm{P}=0.082)$. For $3 \mathrm{~mm}$ of displacement however, there was a statistically significant difference between the groups in the oneway ANOVA $(\mathrm{F}=5.44, \mathrm{P}=0.021)$. Tukey's posthoc test revealed that the new plate exhibited a lower load at $3 \mathrm{~mm}$ of displacement (Mean 98.73 [16.9] N), which was statistically significant when compared with the two locking plates (Mean 131.93 [16.1] N; $\mathrm{P}=0.016)$.

\section{DISCUSSION}

Several plates and screws with different geometric designs have been used in the treatment of mandibular angle fractures [11]. The geometric properties of these materials, as well as the number and location of the screws, have not yet ben definitely demonstrated. Existing practical techniques of internally stabilizing fractures of the mandible are mostly based on clinical experience [12]. The present study demonstrated patterns of stress distribution in the case of a mandibular angle fracture with bone loss.

The geometric configuration and boundary conditions used in the FEA of mandibular fractures are diverse. To simplify the model, the teeth were removed, and the cortical and cancellous bones were modelled in polyurethane, as described in previous studies $[\underline{9}, \underline{10}, \underline{12}, \underline{13}]$. The contact between the segments was generally non-inexistent, with a gap of 1 or $2 \mathrm{~mm}$ [12]. Another model used a $1 \mathrm{~mm}$ callus section, placed between the two fractured mandible sections [13].

In the present study, we elected to apply a displacement of $3 \mathrm{~mm}$ in $\mathrm{z}$ direction above the ipsilateral first molar area. However, the literature contains studies that used bite force in a load point $[9,12]$. We assumed three-dimensional linear elastic behaviour for the entire model and frictionless unilateral contact between each side of the fractured mandible [14].

The new plate exhibited the lowest Von Mises stress values, which could be due to the more uniform distribution of the load on the plate. In Groups I and II, the upper plate exhibited a significant concentration of stress as the upper part of new designed plate. There is less material in the new plate design (eight screws instead of ten) and this plate is thinner than the lower locking plate $(1 \mathrm{~mm}$ instead of
Table 4. Comparison of reaction force values $(\mathrm{N})$ in between fixation groups

\begin{tabular}{l|c|c|c}
\hline \multirow{2}{*}{} & \multicolumn{3}{|c}{ Displacement } \\
\cline { 2 - 4 } & $\mathbf{1} \mathbf{~ m m}$ & $\mathbf{3} \mathbf{~ m m}$ & $\mathbf{5} \mathbf{~ m m}$ \\
\cline { 2 - 4 } & \multicolumn{3}{|c}{ Mean (SD) } \\
\hline Group I & $44.96(8.87)$ & $113.87(14.69)$ & $155.58(25.39)$ \\
\hline Group II & $53.61(9.83)$ & $131.93(16.1)$ & $187.52(19.93)$ \\
\hline Group III & $41.82(9.94)$ & $98.73(16.9)$ & $145.06(36.28)$ \\
\hline
\end{tabular}

$\mathrm{SD}=$ Standard deviation

$1.5 \mathrm{~mm})$. New bone plates can support a greater load than commercially available plates with the same amount of material. In addition, new bone plates can be manufactured with less material to support the same load [15].

During the fracture healing period, the premature failure of plates must be prevented. The loads transmitted through the plates should not exceed the limit of the strength of the material. Screws near the fracture site are exposed to the greatest load [12]. The results of the present study confirmed these ideas, given that the screws near the fracture line and the site of the plates across the fracture exhibited the highest Von Mises stress values.

On the other hand, using more screws and increasing the length of the plates helped to distribute the stress throughout the plates and screws. Distributing the stress improves the rigidity of the system, which can also be achieved by applying a more rigid plate or a second plate [12]. However, alterations to the design of plates, with less material, could improve the distribution of stress and the resistance of the system. In the present study, the reaction forces for the displacements of $1 \mathrm{~mm}$ and $5 \mathrm{~mm}$ were quite similar in all groups.

The locking plate/screw reconstruction system used to treat mandibular fractures has the following advantages over other plating systems: these plates work as internal fixators; and they achieve stability by locking the screw to the plate [16]. A unique advantage of the locking screw/plate system is that the plate does not require intimate contact with the underlying bone, thereby making plate adaptation easier, preventing plate compression on the bone and minimizing bone traction against the plate [17]. To address these advantages in the new plate, it was necessary to include locking. Despite this fact, the mechanical advantages of the locking system may not necessarily reflect in a better clinical outcome, the postoperative complication rate in mandibular fractures does not seem to be influenced by the use of locking plates [18]. 
One limitation of the present study, similar to most FEA models, was the assumption of a perfect bonding union between the bone and screws [ㅇ, 12-14]. This does not occur in clinical situations and it is a significant limitation of this investigation. To reduce the limitation of this analysis, an in vitro test was performed to determine the differences between the groups. However, the complexity of the masticatory system and in vivo conditions can cause fixation systems to behave differently in a biomechanical testing unit [4].

Trivellato et al. [19] performed a biomechanical study to determine the effects of continuity on the inferior border in the treatment of mandibular fractures. The authors used polyurethane mandibles and a $2 \mathrm{~mm}$ titanium fixation system, which was applied according to the technique described by Champy et al. [7]. They found a statistically significant difference for fixation failure in the unfavourable group when the load was applied between the central incisors, confirming that the inferior border of the mandible with continuity provided better results than the inferior border of the mandible without continuity [19]. In the present study, the sample was sectioned in the same manner as the unfavourable fracture, without continuity of the inferior border. However, the aim of this study was to compare techniques of internal fixation. It is important to note that alterations in the load point could modify the mechanical response of the model.

Due to the complexity of the current finite element model and mechanical test, the best form of validation can be achieved through a post-market study. In addition, the developed plate must undergo an optimization process. This could increase the efficacy of current devices while reducing their overall size and cumbersome nature.
The present study has limitations related to the study design. FEA did not incorporate teeth into the simulation. In addition, the model used was specific for a mandibular angle fracture with a segmental defect, and thus, was less generalized for all mandibular angle fractures. This new plate in relation to the osteosynthesis armamentarium will increase the costs once it can only be used for mandibular angle fractures. Finally, the present study contained the limitations inherent to all in vitro investigations.

\section{CONCLUSIONS}

This finite element model confirmed that two 2 $\mathrm{mm}$ locking plates provided more stiffness than the new plate. However, the new plate exhibited a more satisfactory distribution of stress. Furthermore, the new plate modifies the displacement pattern of fractured segments. The present study confirmed that two locking plates promote a better mechanical resistance for complex mandible fractures. Further studies using modifications of the mechanical condition should be performed to determine whether the new design is sufficiently stable to favour the healing of the mandible.

\section{ACKNOWLEDGMENTS AND DISCLOSURE STATEMENTS}

The authors report no conflicts of interest related to this study.

\section{REFERENCES}

1. Gear AJ, Apasova E, Schmitz JP, Schubert W. Treatment modalities for mandibular angle fractures. J Oral Maxillofac Surg. 2005 May;63(5):655-63. [Medline: 15883941] [doi: 10.1016/j.joms.2004.02.016]

2. Alpert B, Tiwana PS, Kushner GM. Management of comminuted fractures of the mandible. Oral Maxillofac Surg Clin North Am. 2009 May;21(2):185-92, v. [Medline: 19348983] [doi: 10.1016/j.coms.2008.12.002]

3. Kovan V. The development of a new mandibular osteosynthesis plate: an application of the Ashby approach. Proc Inst Mech Eng H. 2011 Feb;225(2):199-205. [Medline: 21428154] [doi: 10.1243/09544119JEIM849]

4. Pektas ZO, Bayram B, Balcik C, Develi T, Uckan S. Effects of different mandibular fracture patterns on the stability of miniplate screw fixation in angle mandibular fractures. Int J Oral Maxillofac Surg. 2012 Mar;41(3):339-43. [Medline: 22178275] [doi: 10.1016/j.ijom.2011.11.008]

5. Haug RH, Street CC, Goltz M. Does plate adaptation affect stability? A biomechanical comparison of locking and nonlocking plates. J Oral Maxillofac Surg. 2002 Nov;60(11):1319-26. [Medline: 12420268] [doi: 10.1053 /joms.2002.35732]

6. Marafon PG, Mattos BS, Sabóia AC, Noritomi PY. Dimensional accuracy of computer-aided design/computer-assisted manufactured orbital prostheses. Int J Prosthodont. 2010 May-Jun;23(3):271-6. [Medline: 20552095]

7. Champy M, Loddé JP, Schmitt R, Jaeger JH, Muster D. Mandibular osteosynthesis by miniature screwed plates via a buccal approach. J Maxillofac Surg. 1978 Feb;6(1):14-21. [Medline: 274501] [doi: 10.1016/S0301-0503(78)80062-9] 
8. Rudderman RH, Mullen RL. Biomechanics of the facial skeleton. Clin Plast Surg. 1992 Jan;19(1):11-29. [Medline: 1537212]

9. Cox T, Kohn MW, Impelluso T. Computerized analysis of resorbable polymer plates and screws for the rigid fixation of mandibular angle fractures. J Oral Maxillofac Surg. 2003 Apr;61(4):481-7; discussion 487-8. [Medline: 12684967] [doi: 10.1053/joms.2003.50094]

10. Sato FR, Asprino L, Consani S, Noritomi PY, de Moraes M. A comparative evaluation of the hybrid technique for fixation of the sagittal split ramus osteotomy in mandibular advancement by mechanical, photoelastic, and finite element analysis. Oral Surg Oral Med Oral Pathol Oral Radiol. 2012 Nov;114(5 Suppl):S60-8. [Medline: 23083958] [doi: 10.1016/j.tripleo.2011.08.027]

11. Ellis E 3rd. Treatment methods for fractures of the mandibular angle. Int J Oral Maxillofac Surg. 1999 Aug;28(4):243-52. [Medline: 10416889] [doi: 10.1016/S0901-5027(99)80152-0]

12. Arbag H, Korkmaz HH, Ozturk K, Uyar Y. Comparative evaluation of different miniplates for internal fixation of mandible fractures using finite element analysis. J Oral Maxillofac Surg. 2008 Jun;66(6):1225-32. [Medline: 18486788] [doi: 10.1016/j.joms.2005.11.092]

13. Kimsal J, Baack B, Candelaria L, Khraishi T, Lovald S. Biomechanical analysis of mandibular angle fractures. J Oral Maxillofac Surg. 2011 Dec;69(12):3010-4. [Medline: 21496988] [doi: 10.1016/j.joms.2010.12.042]

14. Fernández JR, Gallas M, Burguera M, Viaño JM. A three-dimensional numerical simulation of mandible fracture reduction with screwed miniplates. J Biomech. 2003 Mar;36(3):329-37. [Medline: 12594981] [doi: $10.1016 / \mathrm{S} 0021-9290(02) 00416-5$ ]

15. Lovald S, Baack B, Gaball C, Olson G, Hoard A. Biomechanical optimization of bone plates used in rigid fixation of mandibular symphysis fractures. J Oral Maxillofac Surg. 2010 Aug;68(8):1833-41. [Medline: 20537782] [doi: 10.1016/j.joms.2009.09.108]

16. Singh V, Kumar I, Bhagol A. Comparative evaluation of 2.0-mm locking plate system vs $2.0-\mathrm{mm}$ nonlocking plate system for mandibular fracture: a prospective randomized study. Int J Oral Maxillofac Surg. 2011 Apr;40(4):372-7. [Medline: 21194892] [doi: 10.1016/j.ijom.2010.11.012]

17. Haug RH, Serafin BL. Mandibular Angle Fractures: A Clinical and Biomechanical Comparison-the Works of Ellis and Haug. Craniomaxillofac Trauma Reconstr. 2008 Nov;1(1):31-8. [Medline: 22110787] [PMC free article: 3052729] [doi: 10.1055/s-0028-1098961]

18. Chrcanovic BR. Locking versus non-locking plate fixation in the management of mandibular fractures: a meta-analysis. Int J Oral Maxillofac Surg. 2014 Oct;43(10):1243-50. [Medline: 25115355] [doi: 10.1016/j.ijom.2014.07.014]

19. Trivellato PF, Pepato AO, Ribeiro MC, Sverzut CE, Trivellato AE. In vitro evaluation of the resistance of a 2.0-mm titanium fixation system in the sectioned angle without continuity of the inferior border of the mandible. Int J Oral Maxillofac Surg. 2014 May;43(5):559-63. [Medline: 24216298] [doi: 10.1016/j.ijom.2013.10.002]

\section{To cite this article:}

Goulart DR, Kemmoku DT, Noritomi PY, de Moraes M.

Development of a Titanium Plate for Mandibular Angle Fractures with a Bone Defect in the Lower Border: Finite Element Analysis and Mechanical Test.

J Oral Maxillofac Res 2015;6(3):e5.

URL: http://www.ejomr.org/JOMR/archives/2015/3/e5/v6n3e5.pdf

doi: $10.5037 /$ jomr.2015.6305

Copyright (C) Goulart DR, Kemmoku DT, Noritomi PY, de Moraes M. Published in the JOURNAL OF ORAL \& MAXILLOFACIAL RESEARCH (http://www.ejomr.org), 30 September 2015.

This is an open-access article, first published in the JOURNAL OF ORAL \& MAXILLOFACIAL RESEARCH, distributed under the terms of the Creative Commons Attribution-Noncommercial-No Derivative Works 3.0 Unported License, which permits unrestricted non-commercial use, distribution, and reproduction in any medium, provided the original work and is properly cited. The copyright, license information and link to the original publication on (http://www.ejomr.org) must be included. 